\title{
Análisis de los directorios privados de información empresarial española
}

\author{
Por Antonia Ferrer y Fernanda Peset
}

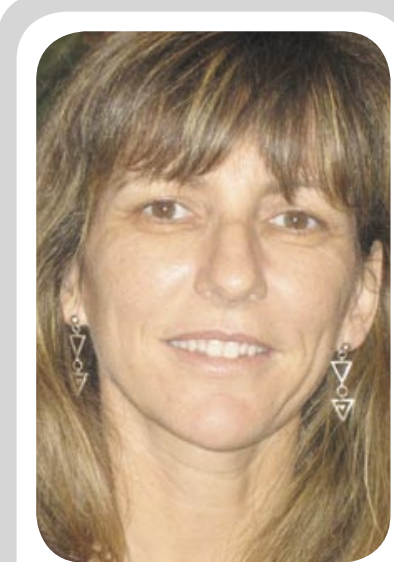

Antonia Ferrer Sapena, licenciada en geografía e historia en la especialidad de historia contemporánea, por la Universitat de $\mathrm{Va}$ lencia (1981) y doctora en técnicas y métodos actuales en información y documentación en 2004. Coordinadora de investigación en Florida Centre de Formació y actualmente profesora de la Universidad Politécnica de Valencia. De los últimos proyectos dirigidos, cabe destacar el portal de Economía Social EcSocial.com http://www.ecsocial.com

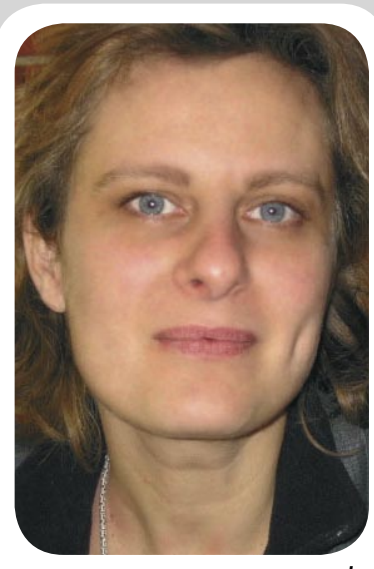

Fernanda Peset Mancebo, licenciada en 1990 en geografía e historia y doctor en documentación en 2002. Profesionalmente de-viene del mundo de las unidades de información y en la actualidad es profesora en la licenciatura de documentación de la Universidad Politécnica de Valencia.

Resumen: Sistematización de las fuentes de información sobre empresas españolas que permite a empresas extranjeras conocer nuestra situación nacional. Su objetivo es ofrecer un panorama de lo que existe, establecer unas categorías sobre el tipo de datos que aportan, y emitir una valoración sobre su utilidad para la captación de clientes. Para ello se han rastreado sistemáticamente las fuentes de información, se han estructurado en una plantilla de evaluación, y por último se han clasificado y descrito de la manera más útil para el objetivo expuesto -captación de clientes y estimación de riesgos-. Como conclusiones se sugieren los formatos de adquisición más pertinentes, las formas de recolección más fiables o las fuentes originarias de los datos. La contribución del estudio se cifra en su utilidad como fuente de información terciaria para establecer negocios en España.

Palabras clave: Información empresarial, Directorios, España.

Title: Business information sources on Spanish enterprises

Abstract: Systematisation of information sources on Spanish companies in order to allow foreign companies to learn about the situation in Spain. The aim is to offer a panorama of what exists, to categorise the types of data provided, and to appraise their usefulness for capturing clients. To do this, the information sources have been searched systematically, structured into a model for evaluation, and finally classified and described in the most useful way for the expressed aims: to capture clients and to evaluate risks. As conclusions we suggest the most relevant acquisition formats, the most reliable collection methods, or the original data sources. The study's contribution is its usefulness as a source of tertiary information for setting up businesses in Spain.

Keywords: Business information, Directories, Spain.

Ferrer, Antonia; Peset, Fernanda. "Análisis de los directorios privados de información empresarial española”. En: $E l$ profesional de la información, 2007, mayo-junio, v. 16, n. 3, pp. 243-257.

DOI: 10.3145/epi.2007.may.09

LO QUE SABEMOS SOBRE LAS EMPRESAS ES FUNDAMENTAL para el desarrollo económico de un país. Esta verdad evidente, como tantas en el mundo de la documentación, tiene un alcance de difícil mesura. La información empresarial la utilizamos todos los ciudadanos que buscamos un proveedor de productos 0 servicios para satisfacer una necesidad de carácter doméstico; y esta necesidad de información se convierte en indispensable cuando un profesional la busca para seguir ejerciendo su trabajo. Ambos requieren lo mismo, pero la magnitud es diferente por su uso final; así que, sea por cifrarlo en la rapidez, en la cantidad o en la calidad, la información que una empresa demanda sobre otra influirá en su trabajo diario y por tanto en la actividad económica nacional.

Otro tópico de la profesión es afirmar que "la información es poder". Pero aunque las empresas la necesitan de manera continuada para que sus negocios sean competitivos, existe una creencia generalizada de que su consumo por parte de la empresa española ha sido tradicionalmente escaso. De hecho, varios estudios han comprobado que es considerablemente bajo (Baiget, 1999; Cornella, 1994, 1996; Aguado; García, 1993). El gasto que representa en las empresas es inferior al que les corresponde si se compara con sus homólogas europeas (Cornella, 1994). Otro indicador, el incremento del número de organizaciones dedicadas a los estudios de 
mercado desde 1994 hasta el 2002, evidencia de nuevo esta afirmación: únicamente existen 24 más en casi diez años (de 187 a 211). A pesar de que hayan transcurrido más de diez años desde su publicación consideramos plenamente vigentes sus afirmaciones.

Convenimos pues que el consumo de información es escaso en nuestro entorno empresarial. Es evidente, sin embargo, que de una empresa puede necesitarse información muy variada, de tipo directorio, económico, estadístico, etc.; aspectos que han sido recogidos en varios estudios por Portela (1996, 1999) con gran profusión. Por su parte, García y Navarro (2005, p. 136) concretan el tipo de datos más demandados en un servicio de información orientado a empresas: de y sobre organizaciones, información y estudios sectoriales, de empresarios, expertos y personas, normativa contable y legislación, referencia de clientes internacionales y buenas prácticas, bibliografía y prensa.

No obstante, debemos señalar que hay un tipo de información de utilización generalizada por parte de un sector de los empresarios: los directorios de empresas. Éstos tienen como fin ofrecer información sobre distintos aspectos: actividad económica y empresarial y datos de localización y contacto. Así, adopta varias funciones indispensables para la labor empresarial: la localización de clientes o de proveedores, la valoración de la fiabilidad de un cliente/proveedor, etc. Como vere- mos más adelante, según el tipo de fuente aportan información únicamente para la identificación de las empresas, o amplían su alcance a datos de tipo económico y empresarial. En este último caso la información ofrecida puede limitarse a la empresa como ente individual o, en las versiones más sofisticadas, informan sobre su posición en relación con el sector de actividad en el que se encuentra inmersa.

\section{"La provisión de información empresarial, sea gratuita o de pago, ha cambiado radicalmente desde que se usa la web"}

La provisión de este tipo de contenidos ha cambiado radicalmente desde que se suministra a través de la web en tiempo real, ya sea gratuitamente o mediante pago. Hasta la popularización de la Red se encontraban mayoritariamente accesibles en soporte papel o cdrom en bibliotecas y grandes organizaciones debido a su elevado coste. La mayoría de directorios de empresas se han venido publicando de forma anual pues esta periodicidad estaba asociada al formato en que aparecían, impreso en papel o en cd-rom. Por ello internet ha supuesto una revolución también en este aspecto: hay actualización instantánea, excepto cuando se captan de fuentes externas. Esto significa que puede hablarse de varias actua- lizaciones al año (incluso diarias), aunque en ocasiones también se edite anualmente.

Este artículo tiene como objeto actualizar los conocimientos sobre un tipo determinado de fuente de información empresarial en España: los directorios de empresas. La globalización de la economía conlleva la necesidad cada vez mayor de conocer a los productores y consumidores de productos y servicios en todo el mundo. Como beneficios, un directorio ofrece una recopilación sistemática de fuentes; su interpretación desde la experiencia diaria y ser fuente de información para promover la inversión extranjera en España.

En estos momentos existen numerosos servicios que proporcionan información sobre las empresas españolas. Analizaremos los que actualmente gozan de mayor popularidad en nuestro país utilizando la metodología siguiente:

- Rastreo sistemático de las fuentes de información.

- Evaluación mediante la parrilla de análisis que detallaremos más adelante.

- Consulta.

- Valoración desde la experiencia en su utilización.

La parrilla de análisis ha incluido la descripción de sus datos básicos y la clasificación de los directorios según ofrezcan un nivel u otro de profundidad. Aunque se ha intentado homogeneizar la ficha de análisis

\section{Nuevos modelos de negocio con internet}

El cambio que el advenimiento de internet provocó en la información para empresas en España sólo fue un pequeño reflejo de los cataclismos que provocó en los países avanzados. En pocos meses distribuidores y bases de datos online que se vendían muy caras cayeron en picado, cosa que arruinó a algunos (NewsNet, Disclosure, Predicasts...). Así, por ejemplo, desaparecieron bases de datos con notas de prensa, memorias, estadísticas, recortes, registros mercantiles, patentes, etc., pues todo ello se empezó a ofrecer gratuitamente desde las webs de las empresas e instituciones, tanto públicas como privadas. Sólo quedaron los que supieron añadir valor a la información, cuando era posible hacerlo, de manera que a los usuarios-clientes les compensara pagar por ese valor. 


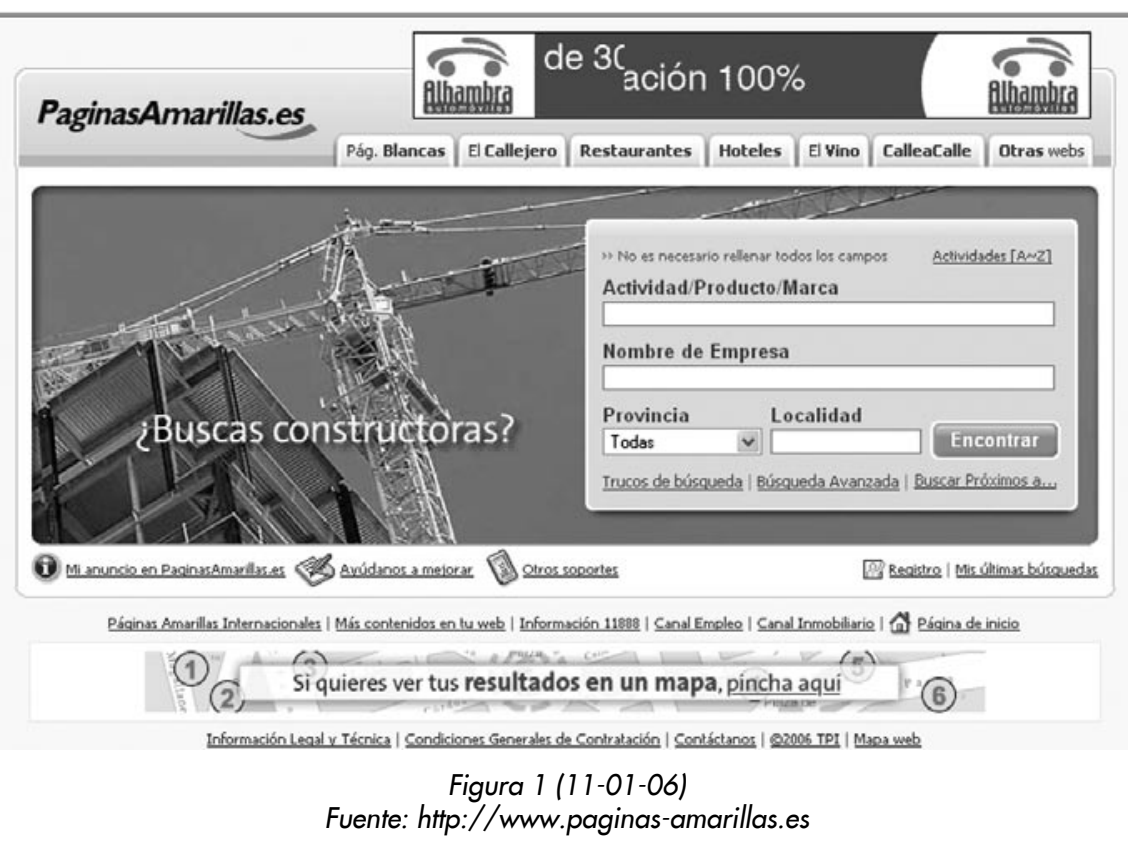

sistemática, ha resultado una labor difícil ya que no existe una estandarización en el modo de recogida de información y en la estructuración de la misma (Ojala, 2005).

\section{Directorios de empresas en España}

\section{Primera categoría}

Ofrecen información mínima, como por ejemplo su nombre, dirección, teléfono, fax o sector de actividad económica. La mayoría la procuran de forma gratuita desde sus webs y suelen estar relacionadas con el suministro de algún servicio telefónico. Quizás los más conocidos sean los de Páginas amarillas de Telefónica o los de Infobel. Su utilidad para los profesionales es bastante limitada mientras que, para los ciudadanos que buscan una empresa concreta o una pequeña selección, son de gran ayuda. Un uso profesional podría ser, por ejemplo, recopilar datos de forma masiva para lanzar una campaña de publicidad. Esto sólo es posible si se contrata el servicio a la empresa suministradora, y hay que señalar que las tarifas varían de manera significativa entre unas y otras.

Una desventaja de las Páginas amarillas es que no aparecen to-
Su principal inconveniente quizá sea que en su versión gratuita no permite guardar una selección masiva y, además, obliga a visitar cada registro para localizar el teléfono de la empresa. Estas trabas empujan a quien necesita grandes volúmenes de información a adquirir ficheros determinados, de manera que Telefónica obtiene ingresos por las empresas que quieren promocionarse y por los usuarios de la información.

El directorio telefónico de $I n$ fobel, por su parte, recoge información de los abonados a las distintas compañías telefónicas a escala mundial. En el caso español incluye Telefónica, ONO o móviles en una base de datos de más de 15 millones de direcciones y números de teléfono de particulares y de sociedades en España (a veces con fax y correo electrónico). Brinda su información de forma gratuita en la web.

El soporte cd incluye mayores prestaciones por un precio módico $(65,29 €$, sin IVA): envío de correos electrónicos a las personas seleccionadas; búsqueda multicriterio en más campos; impresión en etique-

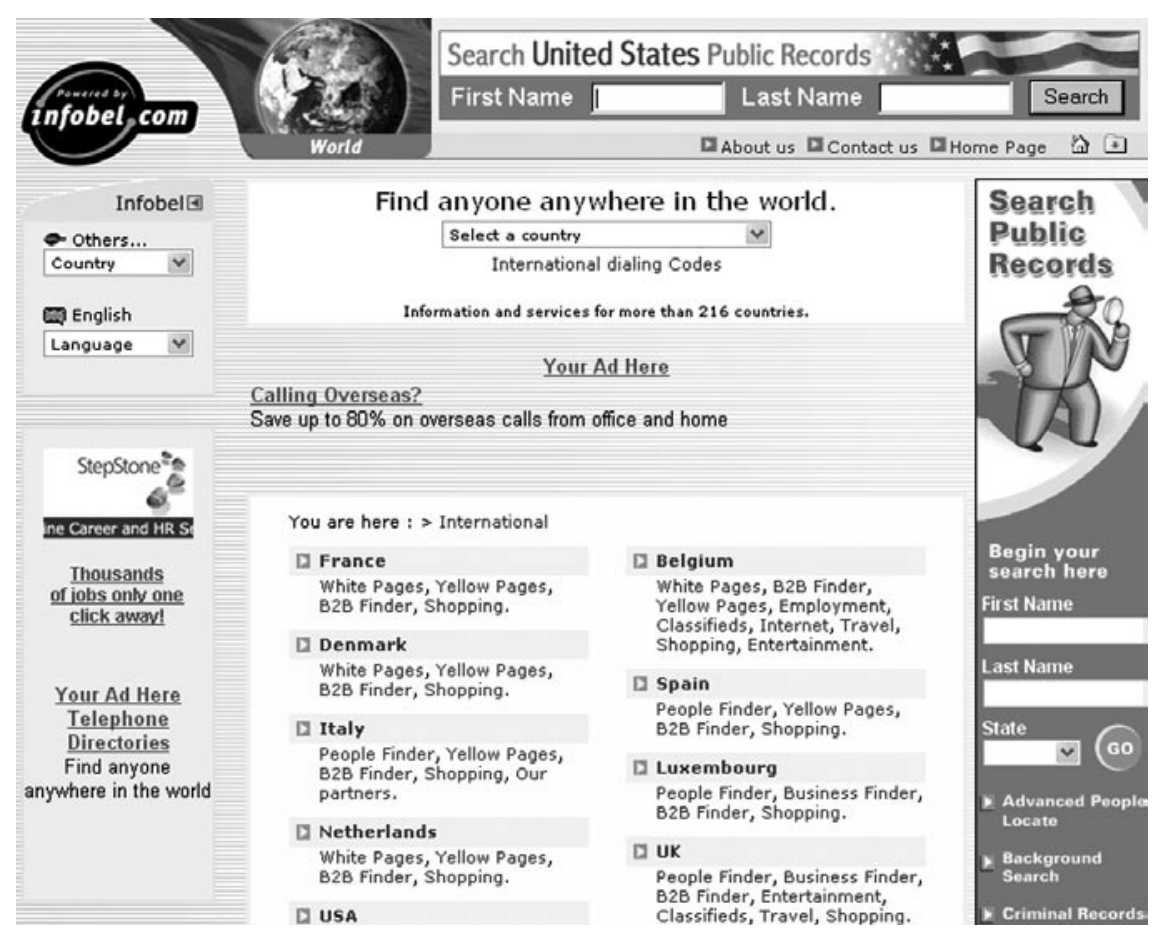

Figura 2 (18-03-05)

Fuente: http://www.infobel.com 


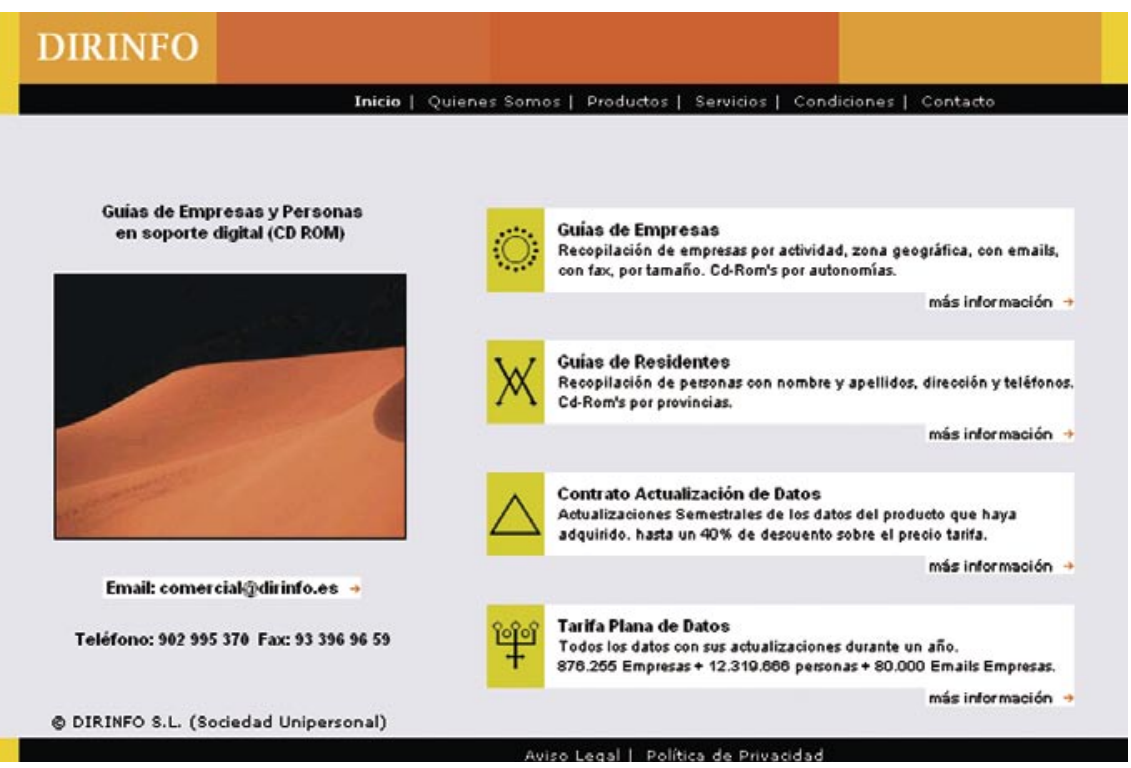

Figura 3 (11-01-06)

Fuente: http://www.dirinfo.es

tas; exportación de datos a distintos formatos de ficheros: dbf, Access, ascii, etc.

Como inconvenientes cabe señalar que, a pesar de contar con información de los abonados a las distintas operadoras de telefonía, en el caso de Telefónica la ofrece menos actualizada que las de Páginas amarillas -y no hay que olvidar que esta compañía cuenta con la mayoría de abonados de nuestro país-. Tampoco incluye la fecha de actualización de la información, por lo que posiblemente sea menos frecuente que en Páginas amarillas. Para documentar este extremo se han realizado búsquedas de abonados recientes, constatando que Infobel no los incluye de manera inmediata. Sin embargo, en sus versiones gratuitas por web Infobel es más flexible a la hora de permitir las consultas. Ambos directorios están sujetos a la ley de protección de datos española, por lo que ninguno permite, por ejemplo, la recuperación de los datos personales de un abonado introduciendo únicamente su número de teléfono, algo que hace unos años era posible en Infobel.

Un directorio similar es Dirinfo, que aporta bases de datos en cd-rom con información sobre particulares y empresas facilitada por yores 100.000 empresas, 250.000 pymes y 350.000 direcciones; la Guía Iron de mayores empresas recoge 210.308 grandes compañías, 210.308 direcciones, 290.136 teléfonos, 44.000 fax, 60.000 emails; o las guías de empresas por comunidades autónomas.

Dentro de esta categoría podemos señalar distintos directorios autonómicos de compañías de economía social que incorporan la información de empresas cooperativas y sociedades laborales. Así en el nivel autonómico de la Comunidad Valenciana disponemos del directorio de Ecsocial.com (Ferrer). Es por el momento único en el estado español, ya que con carácter gratuito permite la consulta de datos básicos de empresas. Actualmente, de esta naturaleza no se encuentra ninguno disponible a través de la Red referido a otra comunidad autónoma.

Los datos de cada las empresas se extraen del Registro Oficial de Cooperativas, lo que supone una fiabilidad extrema, dado que por ley se encuentran obligadas a comunicar a este organismo cualquier cambio que se produzca en la empresa. Como valor añadido ofrece ni las fuentes para ello. Por ejemplo la Guía Gold incluye las ma- los distintos operadores de telefonía. Su actualización es trimestral y facilita la explotación de los datos encontrados en otros directorios. También añade valor a su servicio con las selecciones de empresa que contempla, si bien no especifica los criterios de la selección,

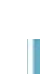

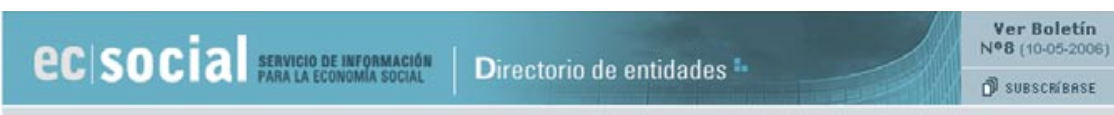

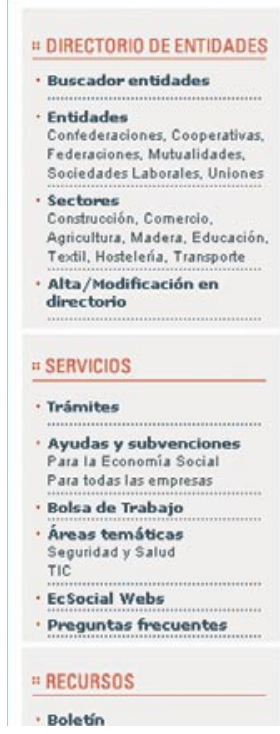

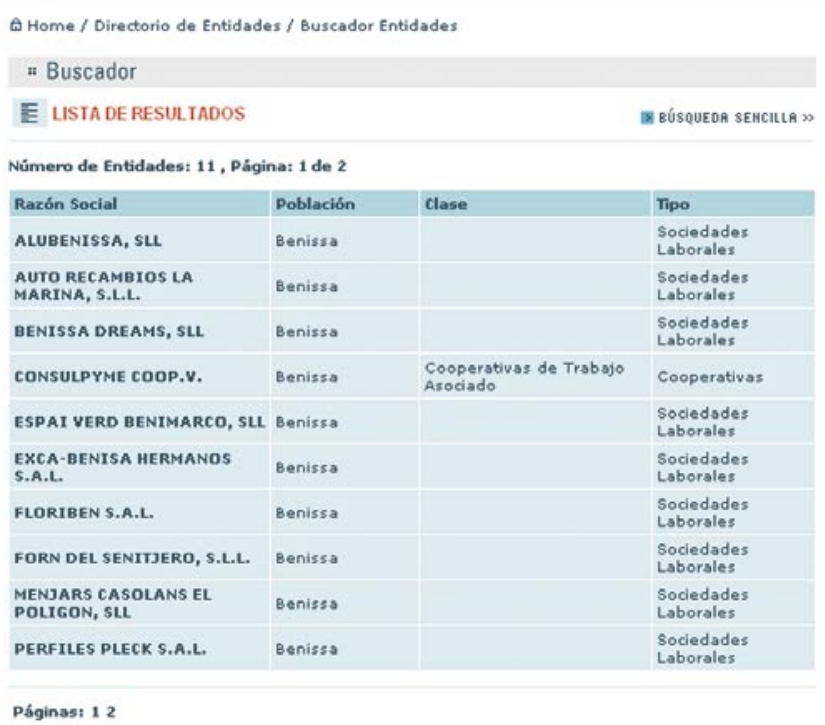

Figura 4 (24-03-06)

Fuente: http://www.ecsocial.com 
DICODI 50.000

Base de Datos de 50.000 Principales Sociedades Españolas, de las que ofrece su información más completa y actualizada.

ANUARIO DICODI 50.000 Compuesto por 1 tomo, que incluye en su interior:

- La Relación Alfabética de Sociedades.

- El Anexo de Estadisticas.

- Un CD de visualización, que permite la realización de segmentaciones por múltiples criterios, mostrando los resultados en pantalla mediante listas, fichas, mapas y gráficos.

CD DICODI 50.000 impresión y etiquetas. Con las mismas características del CD de visualización, permite además la impresión de listas, fichas, mapas, gráficos y etiquetas. CD DICODI 50.000 exportación. Además de disponer de las opciones que el $C D$ de impresión y etiquetas, podrá exportar los datos en dos formatos diferentes (Access y ASCII).
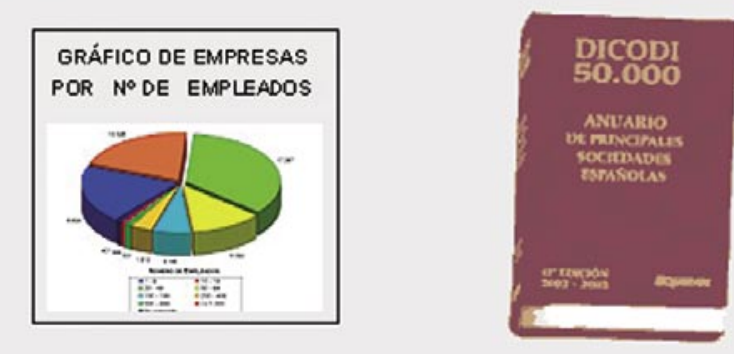

Figura 5 (17-03-05)

Fuente: http://www.dicodi.equifax.es

la posibilidad de crear el web de la empresa y el mantenimiento de los datos por parte del interesado, posteriormente verificados contrastándolos con las fuentes oficiales.

\section{Segunda categoría}

Los directorios que se recogen en este apartado aportan la información de los anteriores además de ciertos datos económicos, como el sector de actividad, el número de empleados, facturación y volumen de ventas. Es difícil realizar una separación total entre los productores que ofrecen información de este tipo y los de la última categoría, pues prácticamente son los mismos agentes que ofertan productos más o menos completos. La razón de diferenciar esta segunda categoría es su utilidad, pues en ocasiones se necesitan datos de empresa a precios asequibles, por lo que no siempre es necesario adquirir el producto más oneroso.

A continuación detallamos los siguientes directorios: Dicodi, Cá- también en cd-rom para impresión y etiquetas o para el sector de la exportación. Otros productos son $\mathrm{Di}$ codi 20.000 Madrid o 20.000 Cataluña para impresión y etiquetas, así como para la exportación.

A la información empresarial básica añade la relativa a nombres y cargos de los principales ejecutivos (más de 125.000 consejeros y directivos), el código $C N A E$, la cifra de ventas, el número de empleados, las fechas de constitución, el capital social, si exporta o importa, gráficos, etc.

De esta manera ofrece como ventaja competitiva conocer las dimensiones de una empresa e identificar y localizar a los posibles clientes potenciales o proveedores alternativos.

Como desventaja cabe citar un aspecto de su fiabilidad. En su sitio web indica las fuentes que lo nutren: los registros públicos del Borme (Boletín oficial del registro mercantil), $B O E$, etc., pero también los envíos de captación de datos que remiten a las empresas. Este procedimiento resulta, sin duda, cuestionable ya que cualquier miembro de la compañía puede cumplimentar la información y remitir los datos sin contrastarlos con la remitida a los registros oficiales. También podríamos matizar la utilidad de acudir a

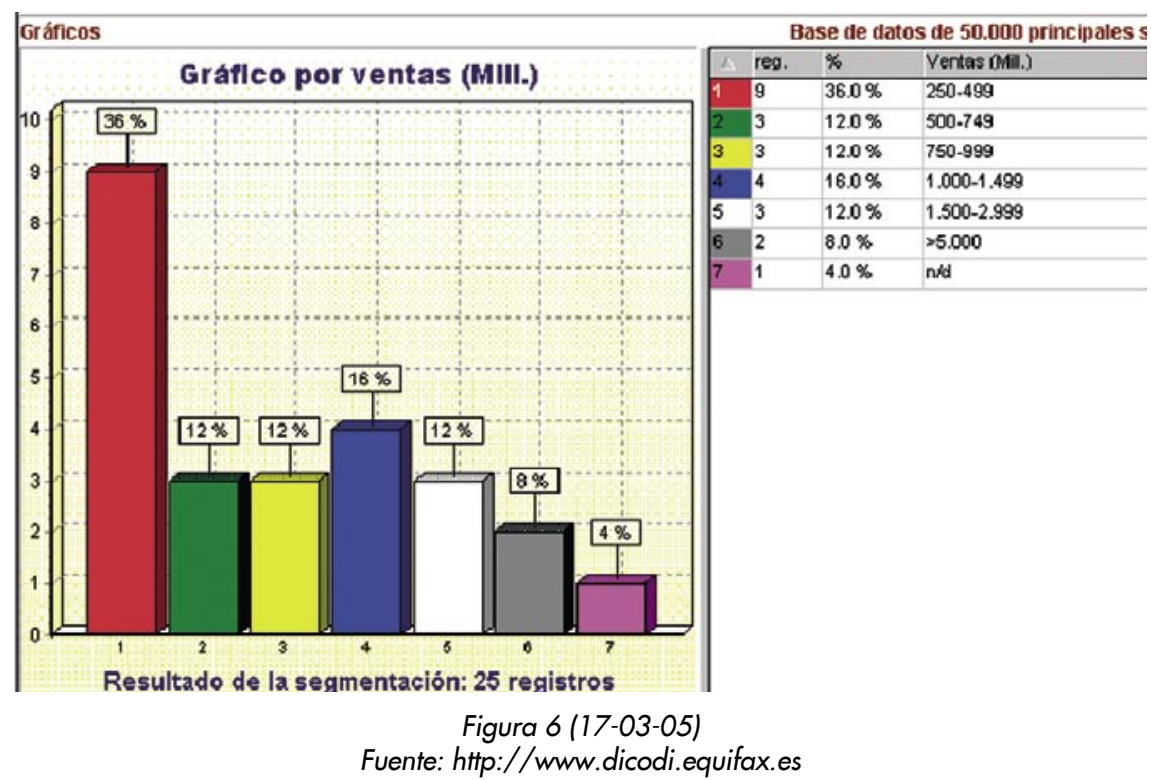


los registros mencionados en dos aspectos. Por una parte, no todas las empresas tienen obligación de depositar sus cuentas en el Registro mercantil ya que, por ejemplo, las cooperativas disponen de uno independiente. Y por otra parte, la información recogida en este órgano suele referirse a dos ejercicios anteriores. Aclarado este extremo, cabe destacar que el anuario Dicodi no especifica a qué ejercicio económico pertenecen los datos.

En conclusión, si adquirimos el anuario Dicodi para elaborar estudios sectoriales será útil. No así si queremos emprender una campaña de marketing, pues el cd-rom de visualización no permite imprimir etiquetas ni exportar la información.

Por su parte, las distintas cámaras de comercio provinciales ofrecen información de las empresas que tienen asociadas, que según la legislación vigente incluiría a todas las mercantiles de su provincia. Cabe distinguir dos niveles de detalle. En el primero ofrecen las empresas de la provincia, producto denominado "páginas salmón" en el caso valenciano. Es decir, cada cámara ofrece la consulta de los datos mínimos de las empresas, ya sea en cd-rom, disco o web, normalmente con una limitación en el número de ítems a visualizar. En un segundo nivel se ofrece información desde la Central de Cámaras de Comercio, un producto denominado $\mathrm{Ca}$ merdata que comentaremos en la tercera categoría.

Una de sus desventajas es que no especifica cómo recoge los datos, de qué fuentes o con qué periodicidad los actualiza. De manera oficiosa se conoce que procede de los distintos registros mercantiles, lo que parece corroborarse al consultar los servicios añadidos que ofrecen de manera conjunta con la Central de Cámaras de Comercio a través de Camerdata.

Los directorios DUNS son de los más relevantes a escala inter-

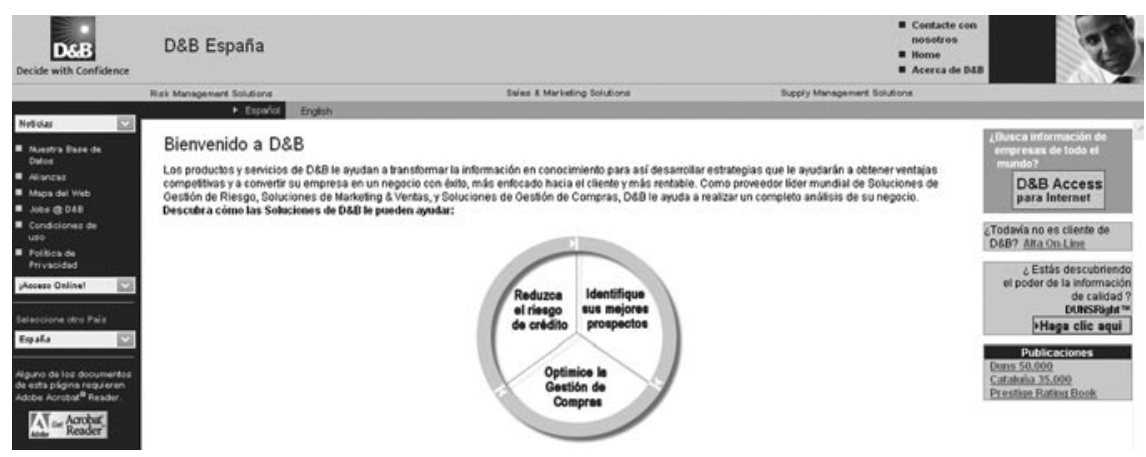

Figura 7 (02-01-06)

Fuente: http://dbspain.dnb.com/Spanish/default.htm

nacional. Los produce por Dun \& BradStreet International (D\&B) con el objeto de valorar la confianza crediticia de una empresa. En noviembre 2005 contaba con 100 millones de registros a escala mundial. $D \& B$ frece productos muy desarrollados para el análisis económico de cada organización, incluso en las versiones papel y cd-rom de la obra. En esta categoría vamos a describir, DUNS 50.000. Principales empresas españolas.

La versión en cd-rom ofrece información, que agrupamos en las siguientes categorías:

- Identificación: razón social, nombre comercial, $C I F$, número DUNS.

- Contacto: dirección, código postal, población, provincia, comunidad autónoma, teléfono, fax, internet.

- Finanzas: ventas, beneficio/ pérdida, patrimonio neto, activo total, capital social.

- Actividad: descripción, código $S I C, C N A E$, código y porcentaje de importación/exportación.

- Directivos: nombre, apellidos y cargo.

- Datos clave: número de empleados, año de fundación, nombre y país de la empresa matriz.

La versión de 2005 ha introducido una serie de mejoras: mapas por provincias y comunidades autónomas; estadísticas de mercado y gráficos así como la posibilidad de escoger empresas con dirección de internet. Las opciones de búsqueda del cd-rom permiten seleccionar por más de 20 criterios de segmentación, obtener listados de empresas y clasificarlos por distintos criterios: código postal, alfabéticamente y por número de ventas o de empleados. Como hemos dicho, ofrece también la representación geográfica en mapas de la selección de empresas y la impresión de fichas.

Otra de las ventajas tradicionales de esta base de datos es su nivel de fiabilidad, ya que cruza la información de distintas fuentes. En su página web detalla el sistema que utiliza para ello, aunque no cita las fuentes. De este sistema, patentado como Entity Matching, resulta el número DUNS que identifica a cada una de las compañías y es utilizado como base de todo el análisis económico que se ofrece de cada organización.

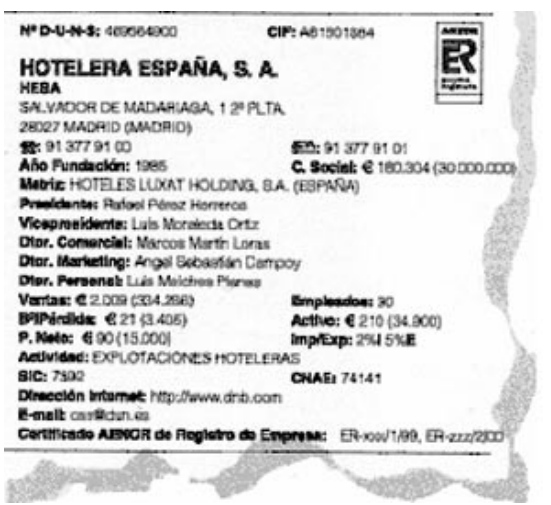

Figura 8

Fuente: D\&B España (02-01-06) http://dbspain.dnb.com/spanish/default. $\mathrm{htm}$ ? Loc $=/$ spanish $/$ SalesMktg/sams duns50000.htm 
De esta manera, la información que proporciona como directorio es útil si queremos conocer de una compañía su trayectoria individual, su posición en el sector, un sector concreto, etc. Pero no permite exportar los datos en formatos estándar como Excel, $d b f$, o ascii. Su problema, por tanto, es que imprime los listados con idéntica apariencia a la versión papel, de manera que es inútil para realizar mailings a empresas. Para obtener otro tipo de productos se tendría que recurrir a DUNS para la compra de datos.

Otro directorio que cabe citar está producido por Kompass, organización dedicada a la promoción de empresas, con 40 años de experiencia en el sector. Ofrece la información nacional e internacional de 50.000 códigos de actividad de productos y servicios en cd-rom, internet y papel.

Debemos conocer todas las formas en que se oferta este directorio, pues según lo vayamos a utilizar para uno u otro fin habremos de adquirir una u otra versión. El cd-rom Scope ofrece 50 criterios de selección para combinar la búsqueda; permite la visualización de fichas y listas e impresión de fichas de empresa una por una. Por tanto no sería útil para lanzar un mailing o analizar un conjunto de datos de empresas. Market 0 es similar al anterior, si bien es posible la selección de empresas para mailings, ya que exporta los datos a otros formatos. Market 1 incluye todo lo anterior y limita la exportación de datos a 5.000 compañías. Además ofrece la información en castellano e inglés. Por último, Market 2 exporta mayor número de datos, 10.000 créditos por edición.

Una de las ventajas de este directorio es la cantidad de campos por los que se puede lanzar la consulta: forma jurídica de la empresa, la fecha de fundación y su capital, directivos, facturación anual, productos, normas, capacidades de

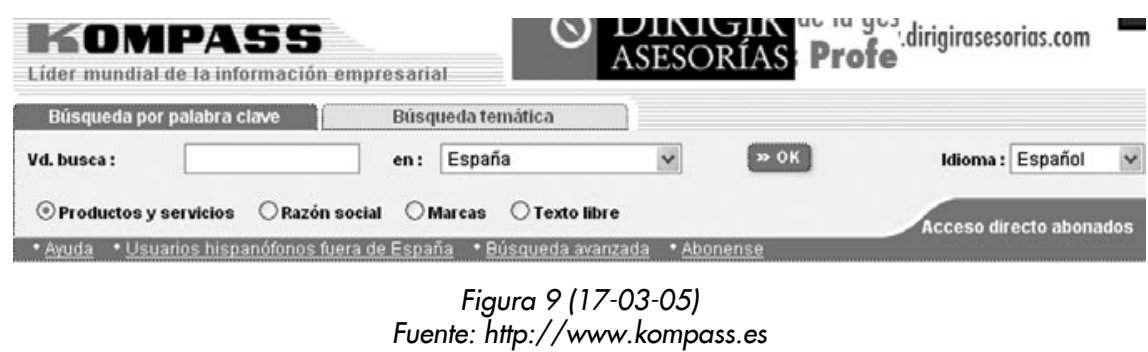

exportación, etc. También destaca por la fiabilidad de los datos de directorio y de actividad económica ya que se recogen mediante cuestionario a la propia empresa, quien además paga por aparecer. La otra cara de la moneda es que la información económica no tiene por qué ser siempre cierta.

Como inconvenientes cabe señalar, primero, que no informa del total de empresas que figuran en los directorios. Tras realizar algunas búsquedas en la versión gratuita de internet, observamos que tiene unos pobres resultados (dos en Jávea, o una empresa en Catarroja). Es un bagaje escaso comparado con otros directorios, ya que por ejemplo la consulta a Ardan (el 10-04-06) ofrecía tres en Jávea ó 31 en Catarroja; mientras que las $P a ́$ ginas amarillas arrojan para Jávea, sólo en el sector de la construcción, 110 empresas o 53 en Catarroja. En

segundo lugar, para exportar datos hay que ponerse en contacto con la empresa editora.

Por su parte Ardan es un servicio de información de reciente creación (1989) del Departamento de Servicios Avanzados de la Zona Franca de Vigo. Actualmente oferta más de 80.000 empresas de toda España. Los productos de Ardan, así como los de Duns, Informa, Infotel, etc., tienen diferentes niveles de profundidad. En este apartado analizaremos el que pertenece a esta categoría: cd-rom de directorio de empresas de las distintas comunidades autónomas, que permite consultar por provincia, actividad, número de empleados y facturación. Hasta fechas recientes (20042005) su información de directorio era de pago tanto en su versión online como en cd-rom. Actualmente la información de directorio es gratuita en ambos casos y únicamente se

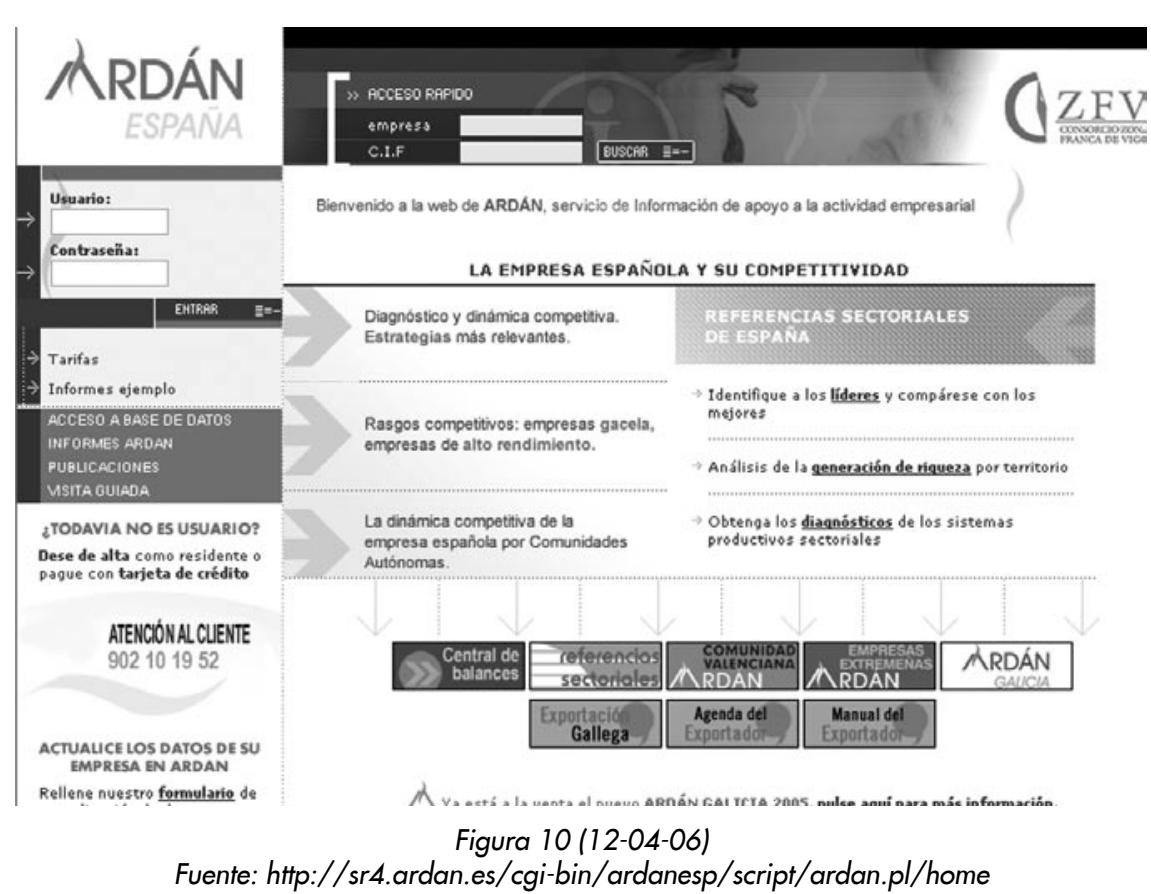


paga cuando se solicita más información sobre la empresa.

Las ventajas de este producto es que permite realizar selecciones rápidas con un mínimo conocimiento del manejo de bases de datos; exporta a otros formatos y su coste es bastante asequible, ya que no funciona por el sistema de créditos que otros proveedores aplican a sus productos en internet.

El único problema de la versión en cd-rom es la incompatibilidad que en algunos casos presenta su instalación cuando en el ordenador existen versiones anteriores o el conflicto con otras aplicaciones de este tipo de otras editoriales. Este inconveniente parece haber sido solucionado en sus últimas ediciones.

La consulta a través de internet ofrece más información que cuando se realiza en cd-rom: aparecen datos de facturación, cash flow, etc. Es algo que también lo ofrecen otros proveedores (SABI, Informa, Infotel, nomefio, etc.) pero Ardan proporciona gratuitamente más datos para empresas concretas.

$\mathrm{Su}$ forma de facturar el producto está basada en un sistema de créditos. Tienen tres tipos de usuarios con tarifas distintas a cada uno de los servicios. Los usuarios residentes abonan un alta de 120 a $200 €$ (que incluye 100 créditos gratuitos, no acumulativo en caso de renovar el contrato), los invitados son los que adquieren la versión cd-rom y los no registrados pagan por cada servicio. Los datos de lo que denominan Bloque $O$ (figura 12) son gratuitos para los residentes y los invitados, mientras que los no registrados han de abonar 0,12 créditos por empresa.

En general la ventaja de la consulta en línea es que permite extraer directamente los listados, etiquetas o exportación de datos a $E x$ cel. Además, en esta base de datos existe la posibilidad de seleccionar uno mismo los criterios de impre-

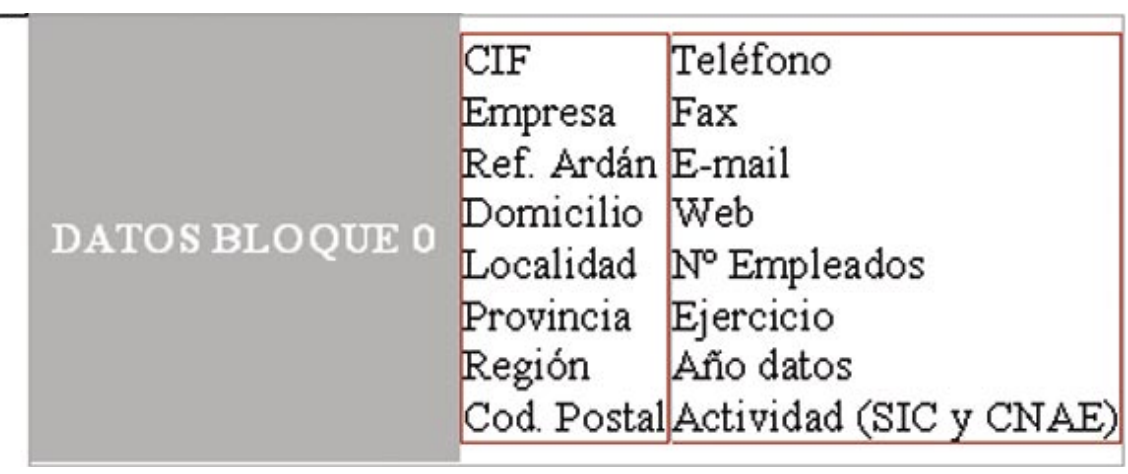

Figura 12 (23-03-06)

Fuente: $h \mathrm{Htp}: / /$ sr4.ardan.es/cgi-bin/ardanesp/script/ardan.pl/home\#

sión y visualización que necesita, variando su coste por cada uno de los campos. Otro de sus puntos positivos es que la inclusión de una empresa no le supone a ésta coste alguno. De nuevo la fuente que alimenta los datos del directorio es el Registro mercantil. Por tanto la información económico-financiera que aporta es de total fiabilidad; dado que, como mencionamos, el retraso de la información registral existe, han incluido otros métodos para mantener esos datos de manera actualizada y como valor añadido aparece un formulario en web donde poner al día otro tipo de datos. Comprueban la identidad de la persona que lo ha cumplimentado contactando posteriormente con la empresa. No indican, sin embargo, si además utilizan otros medios para actualizarlos.
El último directorio que reseñaremos en esta categoría lo publica la empresa que edita la revista Fomento de la producción, siendo una de las primeras en ofrecer en España información de sectores empresariales españoles. De esta editorial hay que resaltar sus publicaciones: Las 2.000 mayores empresas españolas y España 30.000. Pueden consultarse sus contenidos en papel, cd-rom -una copia de su edición impresa, aunque permite extraer etiquetas adhesivas y listados en papel- y web. Los precios de sus productos que aparecen reflejados oscilan alrededor de los 130 y $500 €$ respectivamente para su producto en cd-rom y para bases de datos de marketing. Una imagen de ficha de empresa, que ofrece en su web gratuitamente (de momento), es la de la figura 13. Aunque tiene una cobertura nacional, ofrece especial

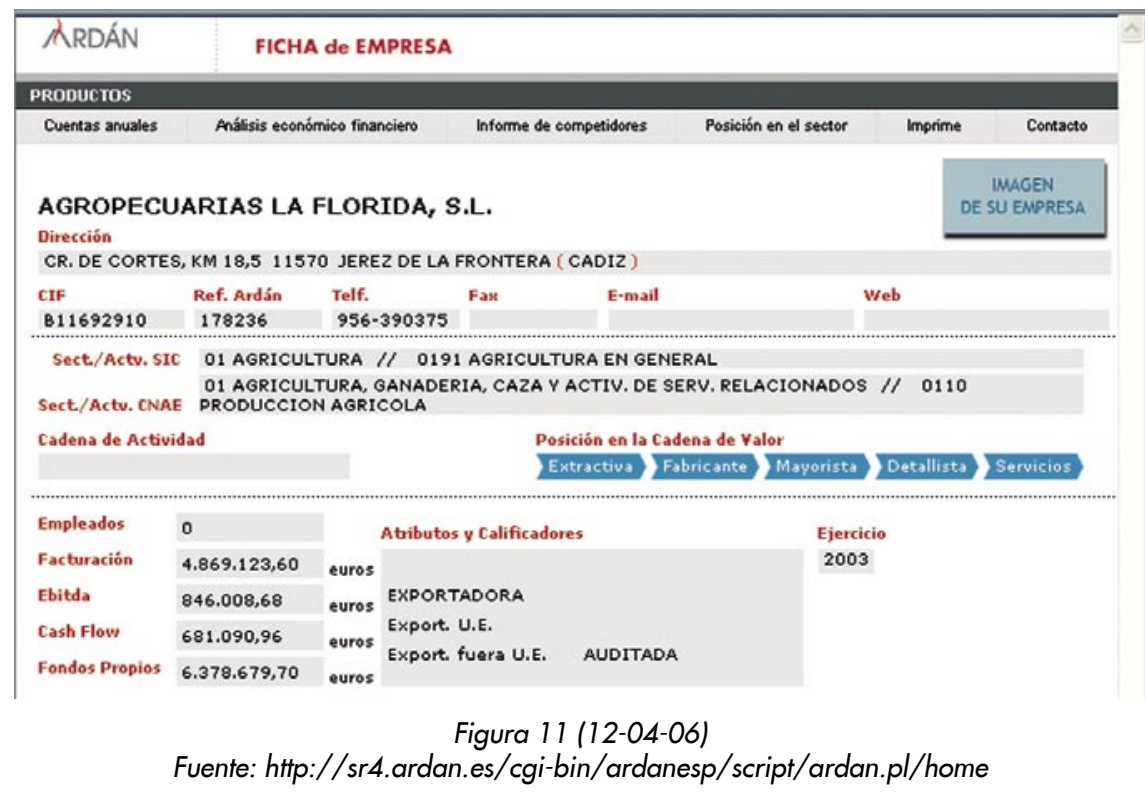




\begin{tabular}{|c|c|c|}
\hline Agrícola Alginet, S & (Coagri) & $F-46024436$ \\
\hline Yalencia, 13 & $\begin{array}{l}\text { Teléfono: } \\
\text { Fax: }\end{array}$ & $\begin{array}{l}961759220 \\
961750327\end{array}$ \\
\hline 46230 Alginet (Valencia) & & \\
\hline
\end{tabular}
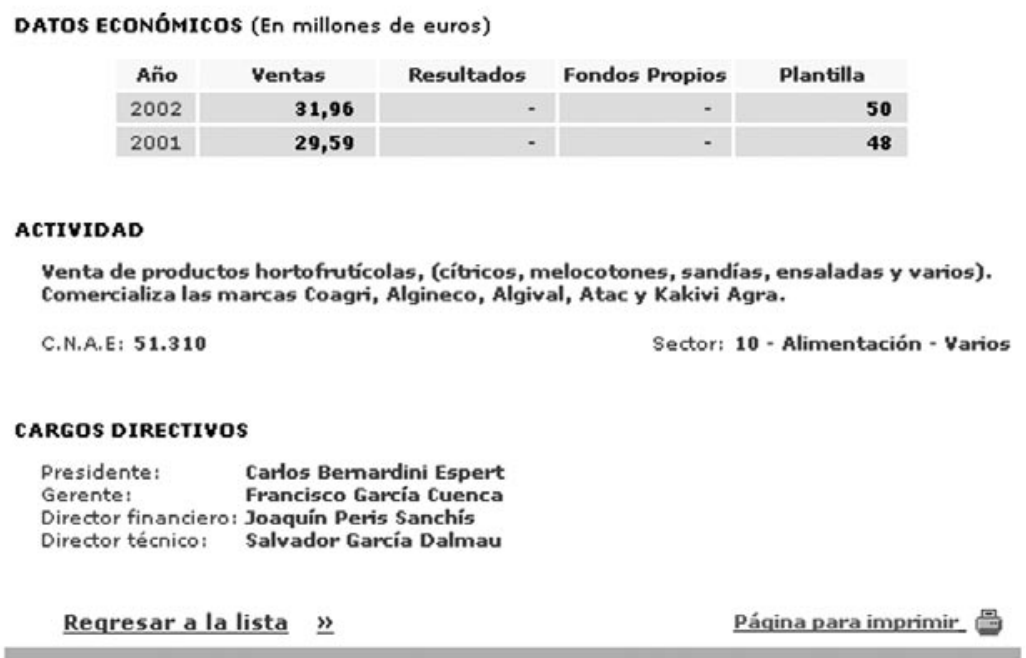

Figura 13 (07-11-05)

Fuente: http://www.fomenweb.com/index.php?e30000=1\&e30busc=1

relevancia a la información empresarial catalana.

\section{Tercera categoría}

Recoge las fuentes que aportan informes comerciales o de seguimiento de empresa. Como señalan García y Navarro (2005, p. 134), la gestión del riesgo se ha convertido en una de las claves del éxito de la gestión empresarial: "identificar els riscos de les operacions, els financers i estratègics, mesurar-los i reduir-los, proporciona més capacitat de decisió i un major avantatge competitiu. Conèixer el possible client fa possible que l'empresa s'avanci a les seves necessitats i li ofereixi productes a la seva mida; a més, permetrà evitar l'acceptació de clientes i treballs que podrien comprometre el bon nom de la firma, la seva dinàmica de treball o els seus recursos, tant econòmics com personals".

Con la introducción de las TIC han proliferado las empresas que ofertan estos productos, ya que la tecnología ha facilitado la importa- ción de datos de diferentes fuentes y su tratamiento puede añadir valor a la información original. Observaremos en su descripción que los primeros productos se ofertan en internet son de la década de los 90 . Tal y como ya se ha señalado an-

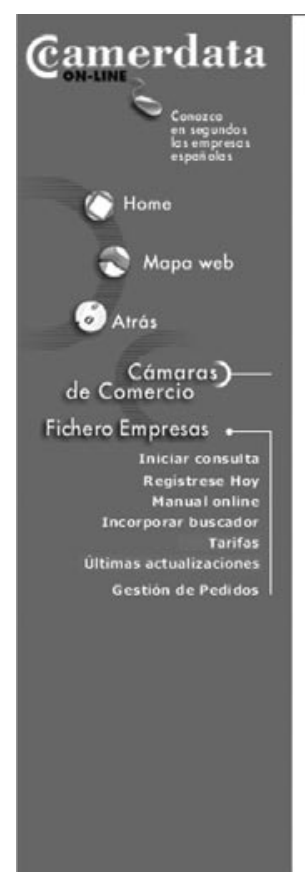

teriormente los productores de este tipo de directorios suelen pertenecer también a las anteriores categorías expuestas:

- Información básica de la empresa.

- Informes comerciales, que incluyen el volumen de negocio, la evaluación del riesgo, etc.

- Información sobre las cuentas de la empresa.

- Seguimiento de las empresas. Por ejemplo, mediante suscripción se pueden conocer los cambios registrales que efectúe una sociedad.

- Seguimiento de administradores y delegados.

- Análisis sectorial.

Los productos más conocidos son Camerdata, Informa, (que dispone del cd-rom SABI: Sistema de Análisis de Balances Ibéricos) e Infotel. Por el contrario, quizás los que menos ofrezcan son Ardán e Infoli$n e$, con tres bloques de productos.

Camerdata es un producto creado por el Consejo Superior de las Cámaras de Comercio y el Instituto Español de Comercio Exterior (ICEX). Su objetivo principal
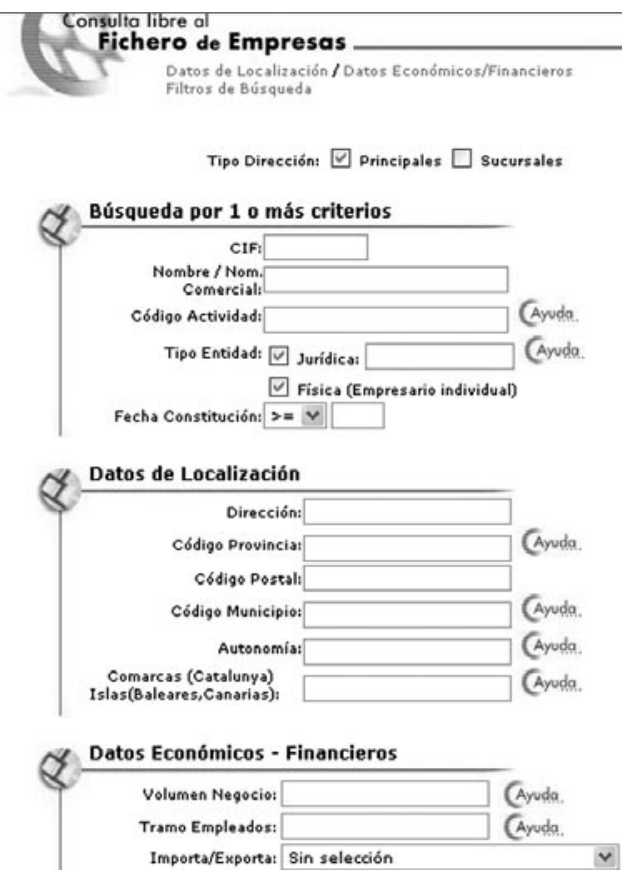

Figura 14 (04-09-05)

Fuente: http://www.camerdata.es:8081/_fichero_empresas/fr_beep.html 
es ofrecer a las empresas servicios de informació22n homogéneos a través del portal de Camerdata. $\mathrm{Su}$ producto más elaborado son los informes completos y ofrecen análisis sectoriales de más de 250 áreas de actividad. En un principio no se distribuían por la Red, pero a tenor de su popularización han fusionado sus servicios para difundirlos a través del web de la Central de Cámaras de Comercio. Los precios varían en función del producto solicitado.

http://www.camerdata.es

En este artículo incluimos los consultados en Camerdata de diciembre de 2006:

- Informe comercial (17 €). Pueden adquirirse de forma independiente los datos básicos de la empresa (incluyendo su balance), su perfil (con ventas de los últimos años, actos del Borme, prensa, administradores, etc.) y el informe de evaluación de riesgo (con opinión, nota, síntesis, incidencias e información judicial).

- Informe financiero (30 €) donde se incluye la información anterior más el balance y la cuenta de resultados.

- Informe completo (45 €): perfil de empresa, evaluación de riesgo, balance y cuenta de resultados, balance comparativo de tres años, cuenta analítica de resultados, ratios financieros ampliados, variación de recursos (estado de origen y aplicación de fondos: $E O A F$ ), grandes masas patrimoniales y análisis sectorial.

La ventaja de este proveedor con respecto a los que detallaremos a continuación no estriba en el tipo de información que ofrece, sino en otros factores como el número de empresas que recoge, la actualización de los datos (úmero de balances aportados en los últimos años y variaciones registrales), facilidad en el acceso y el software de recuperación, la relación calidad/precio y la posibilidad de exportar datos para cruzarlos.

Otra empresa, Informa, es fruto de la alianza entre la Compañía Española de Seguros de Crédito a la Exportación (Cesce) y la francesa ORT. Su objetivo desde los inicios ha sido la aportación de información económica online (comercial y financiera) para minimizar el riesgo comercial. Surgió en 1992 con la proliferación de los servicios de información, aunque no comenzó a ofertar sus productos en la Red hasta 1996. Actualmente el grupo Informa está compuesto por la participación de las siguientes empresas: Experian Bureau de Crédito, CTI, e-Informa, Reintegra, e-Califica,
Grupo Konecta, Infovesa, Informa Colombia, Informa del Perú, D\&B Servicios de Información e Informa $D \& B$ Portugal. Dadas las vinculaciones entre los distintos productores de información consideramos que no es necesario aportar mayor información, para el caso español, de los productos de $D \& B$ y e-infor$m a$. Se alimenta de fuentes de información como el Borme, los Depósitos de Cuentas Oficiales, BOE, boletines oficiales de las CCAA, prensa nacional y regional y distintas publicaciones e investigaciones sectoriales que se realizan.

\section{http://www.informa.es}

Consideramos que, junto al caso anterior, es el productor que aporta la información más fiable. Las cuatro premisas que dice seguir son muestra de ello:

- Sistematización de la información para asegurar la máxima información on-line.

- Orientación a la calidad de productos y servicios buscando siempre la máxima fiabilidad y actualización de la información.

- Apuesta constante por las últimas tecnologías.

- Respeto escrupuloso de la legalidad.

\section{Infonomia,}

la red de innovadores de referencia

El espacio de referencia para el intercambio de ideas y experiencias sobre la transformación de las organizaciones a través de la innovación.

\section{"Disfruta de las nuevas secciones, nuevos protagonistas, nuevas soluciones"}

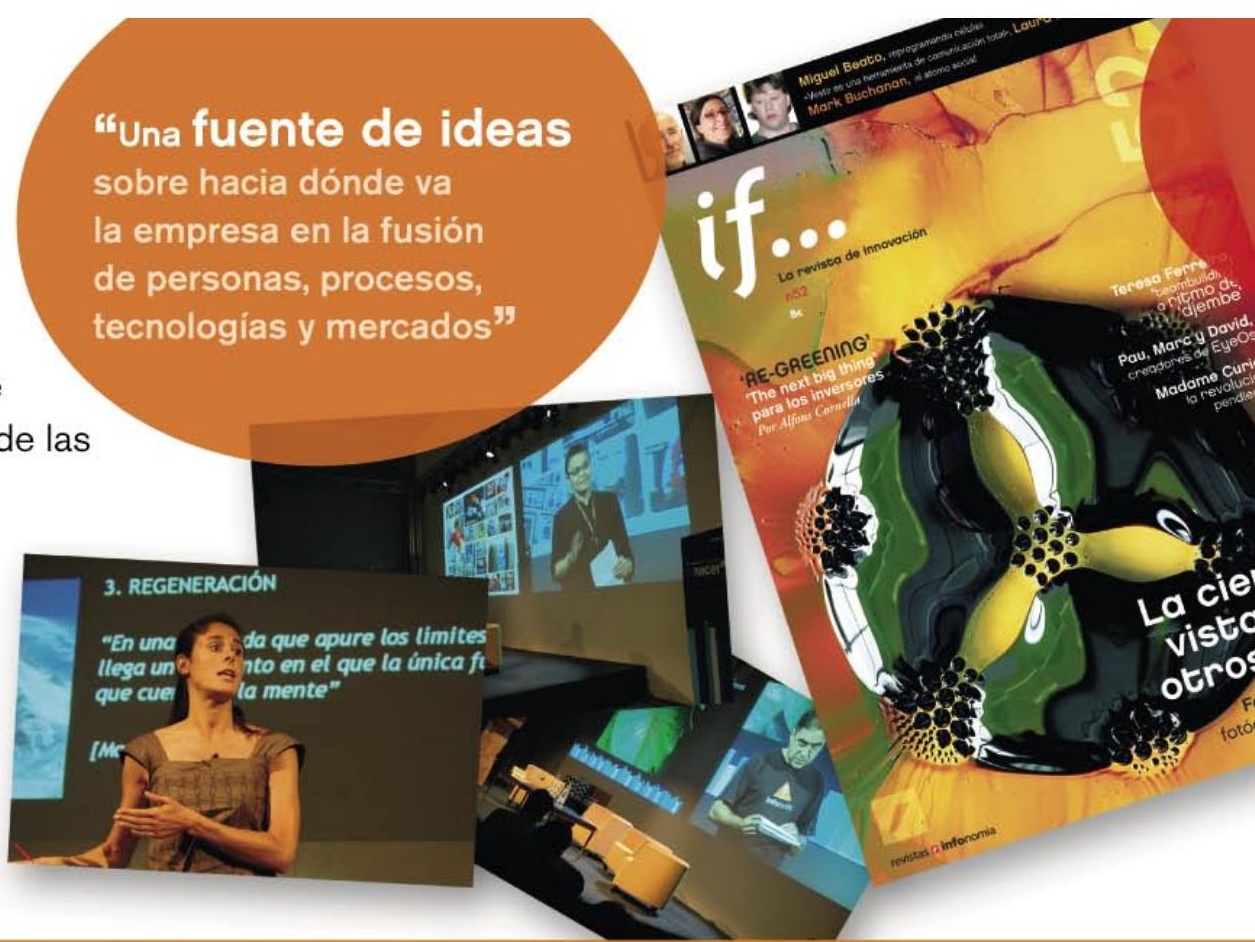


Su producto estrella es $S A B I$, ofertado por suscripción en soporte cd-rom. Se trata de un sistema de análisis financiero sobre más de 550.000 empresas españolas y 60.000 portuguesas. Permite la recuperación por cuentas anuales (con datos históricos desde 1990), razón social, dirección, localidad, provincia, NIF, consejo de administración y ratios de Informa. Además es posible listar las empresas y exportar los resultados en distintos formatos, así como extraer informes personalizados de cada cliente (figura 15).

Otros servicios avanzados son las comparativas entre empresas o la posibilidad de que los expertos de Informa realicen distintos análisis de tipo finaciero: por empresa, comparativo, sectorial y a medida.

Quizás por la fiabilidad y calidad de sus fuentes de información, su producto $S A B I$ es fuente de referencia para los estudios sectoriales de las empresas españolas. Entre sus ventajas, hay que destacar la facilidad de recuperación de la información, exportación de los datos y tratamiento de los mismos, utilidades que otros productores de información no permiten. Con ello, además de posibilitar el análisis de empresas o la comparación entre las mismas mediante rankings, pueden

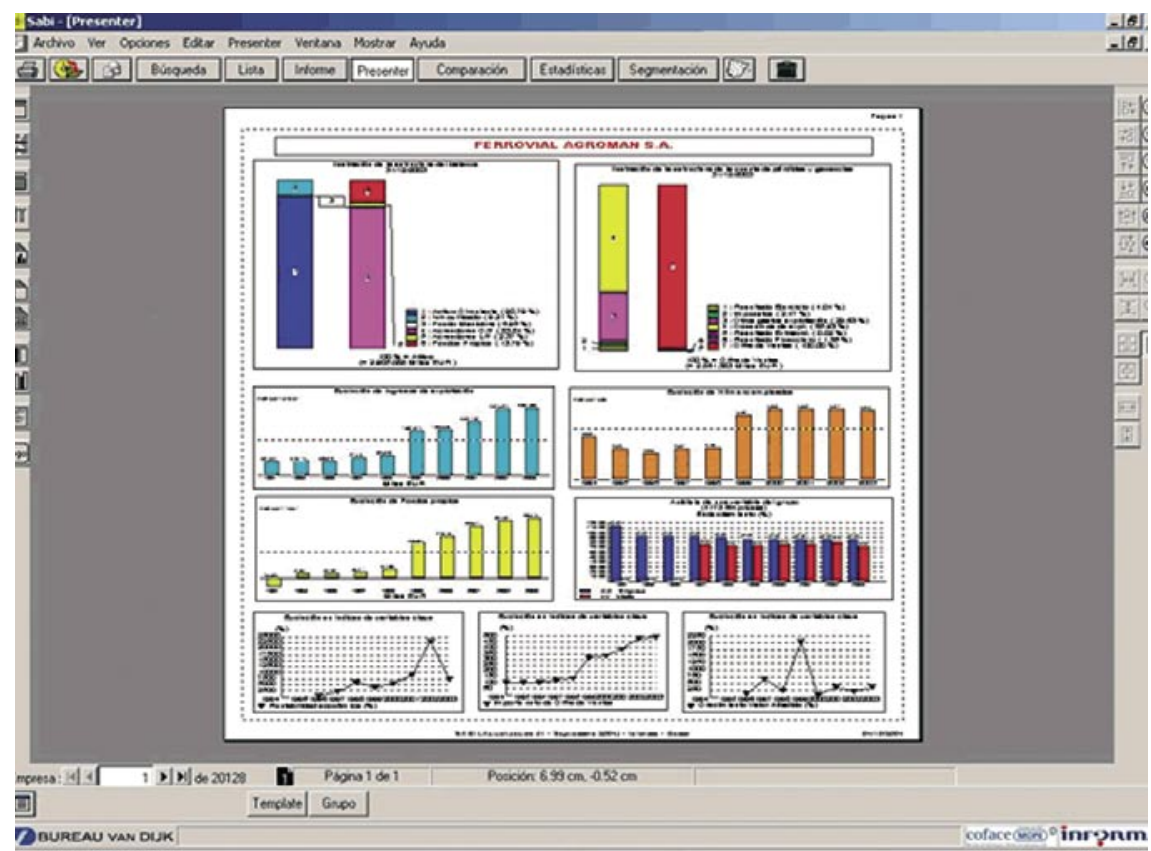

Figura 15 (22-01-06)

Fuente: http://www.informa.es/infornet/Main/idioma/01/screen/SShowPage/pagina/sabe_ 3.html

elaborarse estudios de carácter macroeconómico y microeconómico, así como de seguimiento de empresas, con sus fusiones y adquisiciones. Hay que destacar, además, que fue una de las primeras compañías en ofertar las vinculaciones por directivos.

Quizá la única desventaja a la hora de adquirir este producto es su elevado coste, que sólo tiene sentido si el análisis que efectuemos sobre la empresa tiene como objetivo alcanzar un beneficio que compen- se la inversión. Por ejemplo, sería rentable si interesa un análisis detallado de competencia, sectores, empresas, etc.

E-informa pertenece también al Grupo Informa, como hemos mencionado y oferta: informes de empresas, informes internacionales, información sobre dirigentes y vinculaciones, listados de marketing e informes sectoriales (cuyo autor es un profesor de la Universidad Complutense de Madrid) entre otros productos. Algunos de ellos

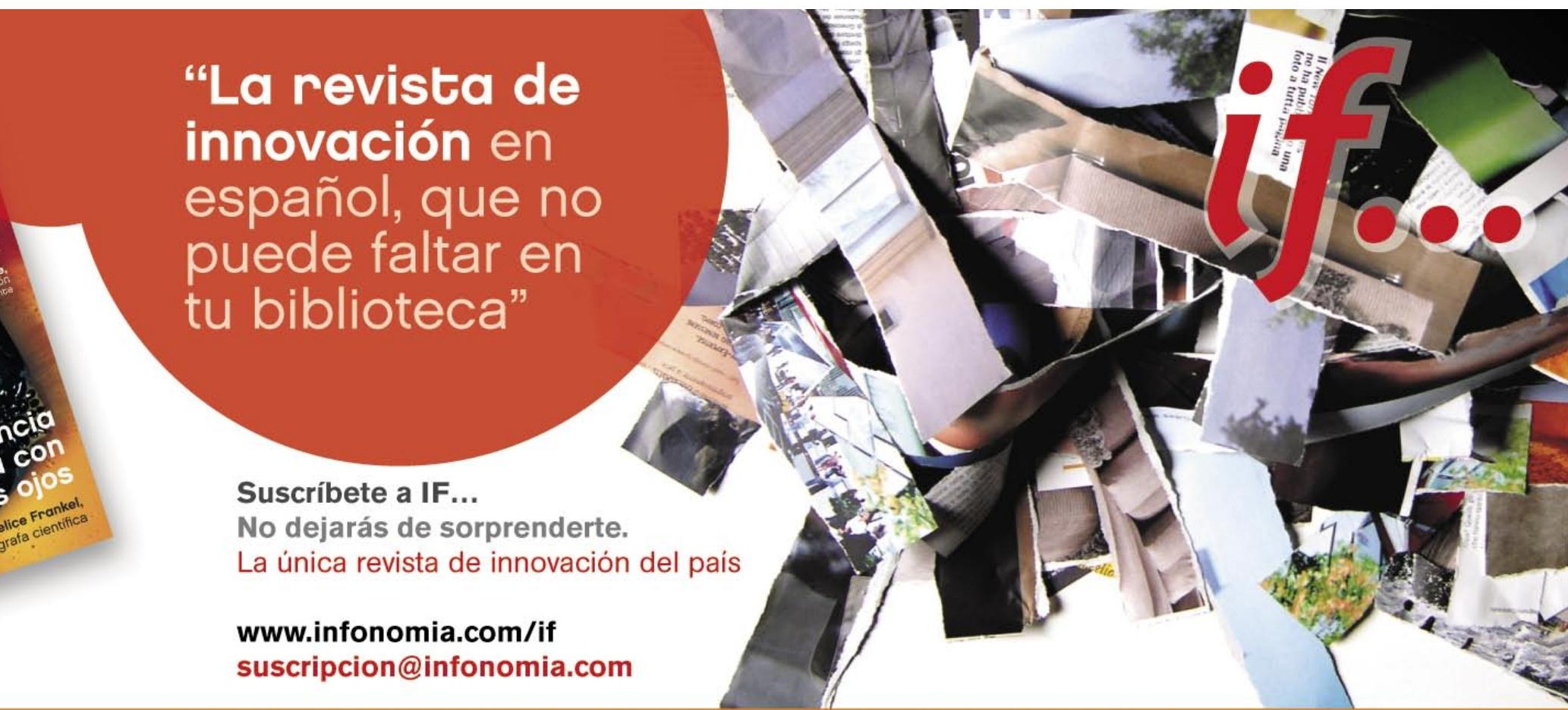




$\underbrace{\text { Potencial Financiero }}_{\text {Medio }}$

Mercantil e Incidencias

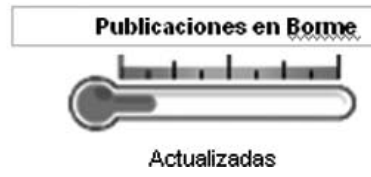

Actualizadas

Positivo

Positivo

田

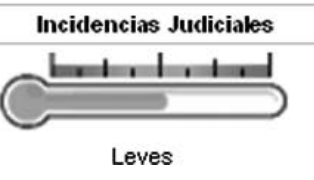

Figura 16 (12-01-04)

Fuente: http://www.axesor.es/

los ofrece gracias a convenios con Camerdata, como es el caso de los listados de empresa para búsqueda de nuevos clientes.

\section{http://www.e-informa.com}

Cabe destacar que en esta categoría detalla las fuentes de información de empresa que utiliza y que, a diferencia de la mayoría de proveedores no sólo se circunscribe al Borme sino que también incluye el boletín oficial de las provincias, boletines oficiales de las comunidades autónomas, boletín oficial del estado y prensa.

Axesor (anteriormente Infotel) es una empresa granadina fundada en 1996. Desde su creación se especializó en la oferta de información empresarial a través de internet. Sus principales productos son los de información de empresas (que consideramos en este artículo), marcas y dominios, gestoría virtual, marketing, boletines e instrumentos jurídicos (Guallar; Cornet, 2004). Al igual que e-informa, Carmedata y otros productores similares ofrece: informes comerciales, datos mercantiles, órganos sociales, demandas judiciales, vinculaciones societarias, sistemas de evaluación de riesgo, calificaciones crediticias y datos económico-financieros, así como una base de datos para marketing. Es aliada de la empresa Duns \& Bradstreet y ofrece información a gran número de países y portales.
Como ventajas cabe citar que la información que ofrece es muy completa. Además, el método de búsqueda y recuperación es bastante rápido y aporta la información de forma organizada, como puede observarse en la figura 16.

Inforinvest, es una empresa de larga trayectoria, 40 años, que estaba especializada en los boletines de morosidad. Fue una de las primeras en ofertar sus servicios a través de la Red. Quizás sea una de las menos conocidas en el campo de los directorios para mailings, pero también disponen de esta información. Exactamente puede encontrarse información sobre: incidencias y solvencia, calificación crediticia, fichero de empresas, registro mercantil, registro propiedad, patentes y marcas, informes comerciales, informes internacionales y balances.

\section{http://www.inforinvest.net}

Uno de sus inconvenientes es no indicar cuál es la fuente de donde extraen la información (aunque suponemos que de registros oficiales) así como la frecuencia de actualización.

Infoline es una empresa de creación relativamente reciente, aunque quizás sea una de las más conocidas en nuestro sector al habérsele otorgado el premio Information world en español en 1994. La oferta de información está referida a: cuentas anuales, memoria anual, estatutos, accionistas, informes de las empresas que cotizan en bolsa, y folletos de emisión y admisión. Sin embar-

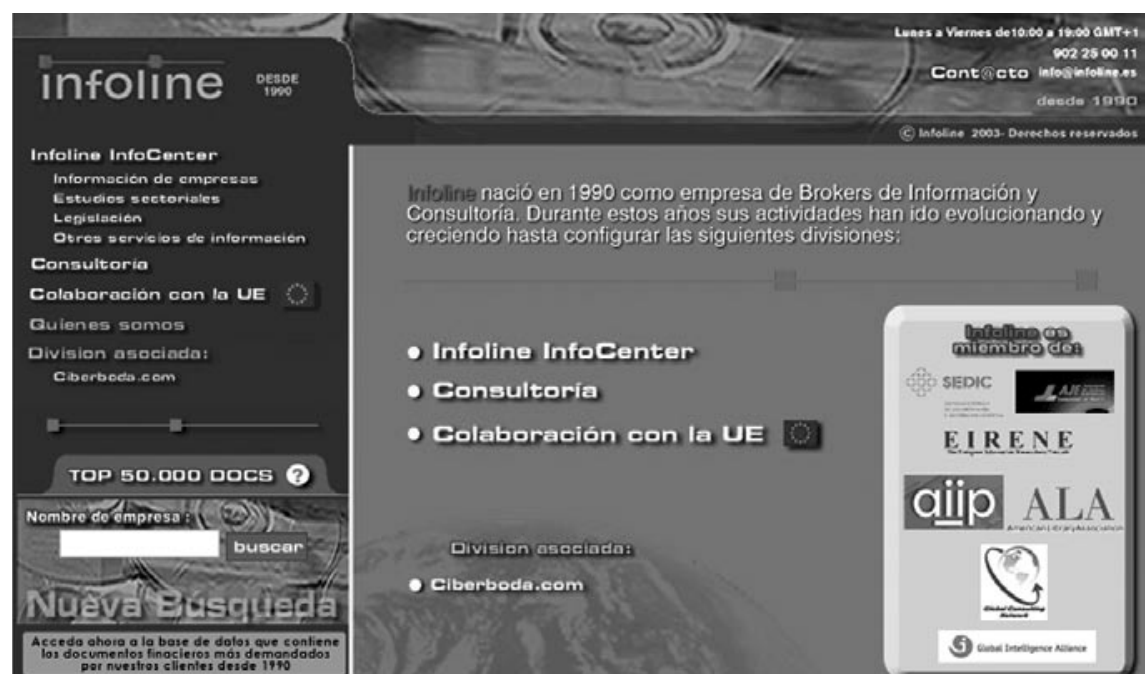

Figura 17 (09-04-06)

Fuente: http://www.infoline.es/ 
go no es consultable en línea: la petición se hace a través de un formulario web o por teléfono.

\section{http://www.infoline.es}

$\mathrm{Su}$ gran desventaja por tanto es que su oferta de productos online es de las más pobres. Además únicamente tiene una opción de búsqueda general y aparece información de las grandes empresas. Al realizar una consulta de pequeñas compañías hemos comprobado que no constan en su directorio. Tampoco figura cuál es la fuente de información de la que proceden sus datos.

Nomefio es un distribuidor de información empresarial que tuvo gran impacto cuando apareció, ya que publicaba la información de las empresas, seguimiento y otros productos de manera gratuita (lo que sólo era cierto hasta un primer nivel). Posteriormente se hizo famosa por las desavenencias surgidas entre los socios y los dominios registrados.

\section{http://www.nomefio.es}

Actualmente figuran en este dominio desde el 2002. Oferta:

- Directorios de empresas.

- Información sobre cargos y dirigentes.

- Información mercantil, comercial, financiera y judicial de empresas.

Una de sus ventajas era que ofrecía gratuitamente a los usuarios registrados una pequeña parte de la información: datos identificativos de la empresa y consulta de las inscripciones publicadas en el Borme; detalle de las incidencias judiciales publicadas a excepción de los últimos 2 años, etc. Pero en estos momentos, el servicio es de pago, lo que la convierte en un producto similar a los anteriores. Teniendo en cuenta que extrae los datos también del Borme y publicaciones oficiales, y habiendo constatado mediante consultas (cuando era gratuito) que los balances que ofrecía eran del año 2000-2001, hay que concluir que es menos competitivo que, por ejemplo, la base de datos $S A B I$.

La oferta de los productos $A r$ dán sobre informes financieros, competidores, etc., es relativamente reciente aunque la empresa, ya descrita, se creó en 1989. Comparando el producto de diagnósticos de los sistemas productivos sectoriales con el de otros productores, como Camerdata, observamos que ofrece un número inferior de sectores, lo que lo convierte en menos competitivo: alimentación; construcción y obras públicas; electricidad, energía y agua; industria auxiliar; información y conocimiento; madera, mueble y actividades relacionadas; maquinaria y equipo; productos químicos y derivados; textil, confección y moda; y turismo, viajes y ocio.

Por último, Equifax es una empresa de larga historia que inicia su trayectoria en España en 1994, pero quizás sea de las menos conocidas en nuestro ámbito. Ya la hemos visto en la categoría anterior como autora de uno de los directorios de empresa más conocidos en España: Dicodi. Al igual que el resto de compañías mencionadas anteriormente también ofrece información sobre las cuentas, estados financieros e información comercial de las empresas. A través de Equifax puede accederse al fichero de impagados Asnef y la empresa está especializada en aportar información de impagados a las entidades financieras.

\section{http://www.equifax.es}

\section{Conclusiones}

A lo largo de estas páginas se ha ofrecido un panorama de la situación española que permita a posibles inversores consultar las fuentes más estables y fiables para conocer el tejido empresarial nacional. Como en todos los trabajos de esta índole, no están todos los que son, pero sí son todos los que están más allá del objetivo mínimo que es la generación de etiquetas para campañas masivas de correo con el objeto de captar clientes.

Ahora bien, del estudio se infieren una serie de conclusiones que tienen implicaciones más allá de la individualidad de cada una de las fuentes de información. Los aspectos que cabe destacar se refieren a: los costes relativos en función del uso que se va a dar al directorio,
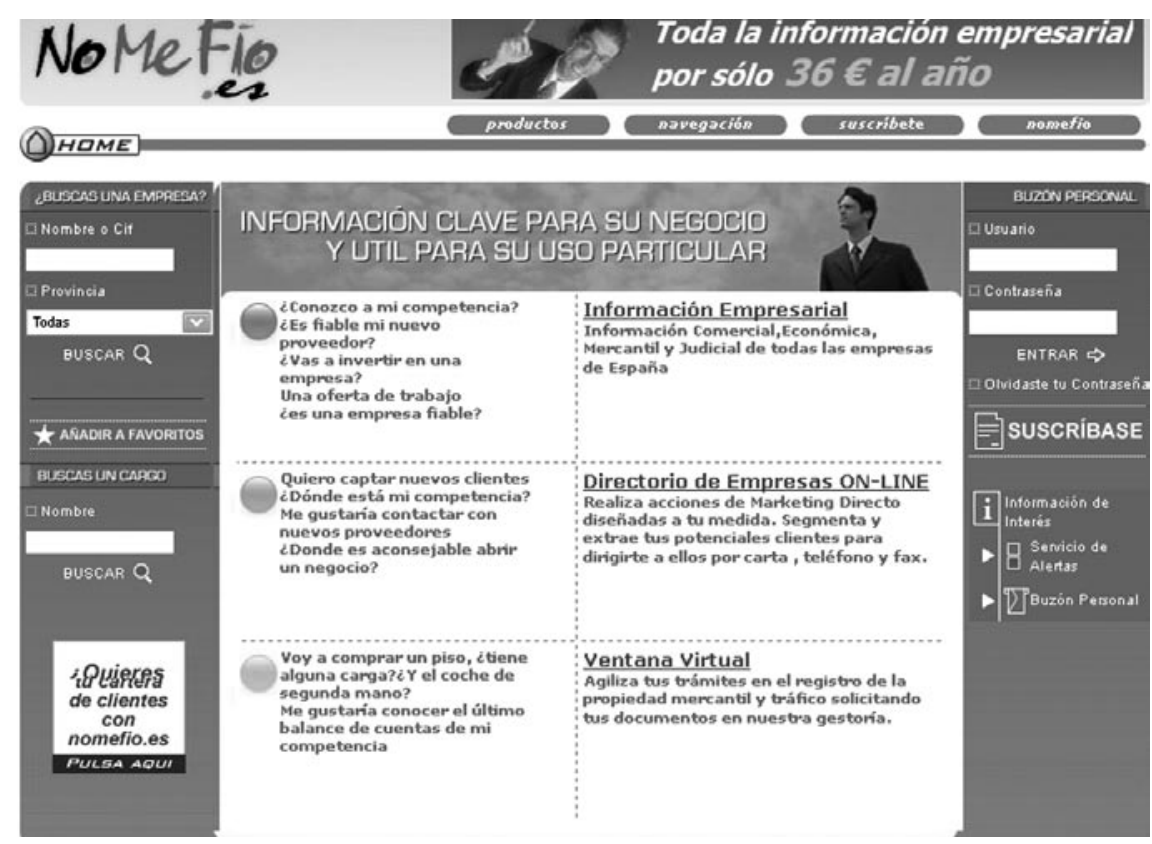

Figura 18 (13-05-06)

Fuente: http://www.nomefio.es/ 

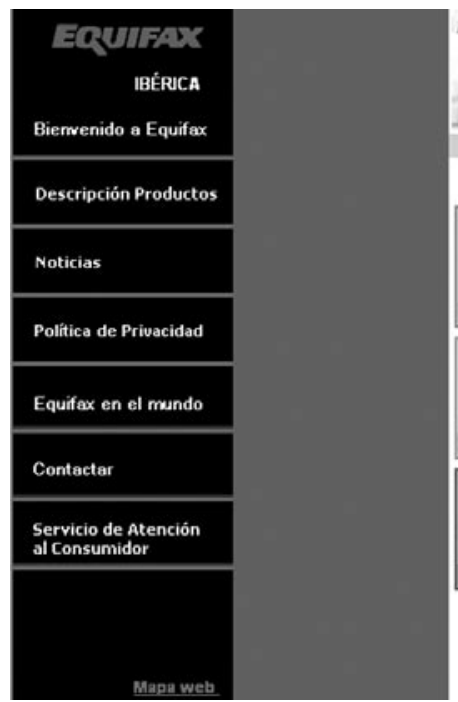

Bienvenidos a

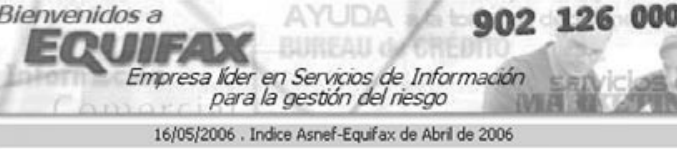

D> Acceso Equifax España D> Acesso Equifax Portugal

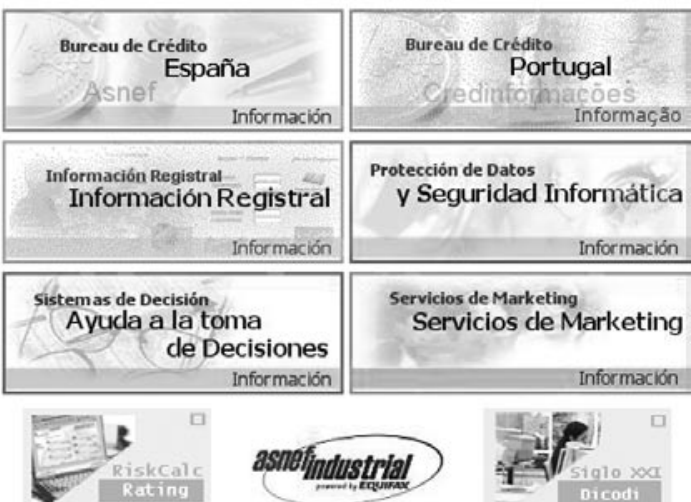

Figura 19 (09-04-06)

Fuente: http://www.equifax.es/ el formato de distribución, la fiabilidad de los datos, sus fuentes de origen, los métodos de recopilación y actualización de la información, etc.

Vayamos por partes. En primer lugar, la adquisición de productos en cd-rom es procedente cuando el poder adquisitivo de la empresa no es muy elevado y necesita realizar continuos mailings para captación de clientes. La oferta de los distintos servicios de información del grupo de tercer nivel en muchos casos excede las posibilidades o disposición de las empresas para envío de mailings. De esta manera, adquirir los productos de Ardan, Dicodi o Fomento de la producción puede ser apropiados. Cabe señalar que con los de la primera categoría (directorios telefónicos) se pueden obtener etiquetas, pero los criterios para seleccionar el grupo de empresas no son cualificados, ya que no pueden interrogarse por cantidad de empleados, por ejemplo, información que es vital en ciertas campañas de marketing (cursos de formación). Por el contrario, para una institución académica que haya de realizar también estudios económicos, indudablemente es $S A B I$ el producto a adquirir. Su coste 9.000 $€$ puede amortizarse si su utilidad va a ser maximizada.

En segundo lugar, en función de las necesidades habrá que elegir cuál es el soporte más adecuado. Cada vez es más popular y crece el uso de los directorios a través de internet. Esta popularidad se produce tanto a nivel nacional como internacional. Algunos estudios, de hecho, auguran la desaparición del soporte papel en la publicación de los directorios (Ojala, 2005), ya que las ventajas que representa la edición electrónica son obvias: actualización constante de la información, nuevas formas de tarificación, como el pago por consumo, etc.

En tercer lugar, sobre la fiabilidad de los datos recogidos y sus fuentes de origen cabe matizar que, si bien la manera más recomendable es acudir a los registros oficiales, esta metodología, según hemos visto, también es discutible. En España existen dos tipos de registros para inscribir las empresas, regulados por diversa normativa para su constitución, el procedimiento de inscripción o la comunicación de la variación de datos: artículo 16 del código de comercio y normativa de desarrollo para las sociedades mercantiles, y para las cooperativas legislación autonómica y/o estatal en su defecto.

Si se trata de una empresa mercantil (sociedades comanditarias, sociedades anónimas, etc.) se inscribe en el Registro mercantil de cada provincia o en el nacional según su ámbito de actuación. La información que se registra aparte de los datos básicos son los depósitos de cuentas anuales, en la que aportan información de sus balances, cuentas de pérdidas y ganancias, memoria e informe de gestión, etc. Si se trata de una empresa de la economía social (cooperativas, sociedades laborales, etc.) se inscribe, en cambio, en el Registro de cooperativas, al que se aporta algo similar. El problema vendría por la actualidad de los datos, ya que aunque toda empresa está obligada por ley a comunicar cualquier modificación al registro respectivo, normalmente no se cumple al no existir sanción por incumplimiento. Por ello, la información que reflejan suele estar desactualizada o ser inexacta. Por otra parte, extraer la información de los registros oficiales encarece el producto final, dado que éstos cobran no sólo a la empresa por inscribirse, sino también a los productores de fuentes de información económica por suministrársela.

Y en cuarto y último lugar, en cuanto a los métodos de recopila-

\section{"Se ha ofrecido un panorama de la situación española que permita a posibles inversores consultar las fuentes más estables y fiables para conocer el tejido empresarial nacional"}


ción y actualización, una vez conocidos los límites de acudir a los registros oficiales, convendremos en que los productores de este tipo de información deberían instrumentar medidas correctoras de los datos. La primera de ellas, obviamente, es contrastar la información extraída de los registros, aspecto difícil ya que la información contable de las empresas es celosamente guardada por las mismas. Dado que actualmente no existe sanción por incumplir la norma de aportar los datos contables anualmente al registro mercantil o de cooperativas, las empresas no ejecutan puntualmente esta obligación. Además hay que hacer notar el retraso a la hora de registrar la entrada de esta información en los distintos archivos administrativos.

En resumen, como todo proveedor de información, los productores de información económica de la primera y la segunda categoría no hacen más que reelaborar aquella que recopilan o que extraen de otras fuentes. Para ganar clientes es fundamental que añadan valor a sus productos como pueden ser: búsquedas multicriterio; exportación de datos para distintos fines en diferentes formatos compatibles ( $x l s, d b f$, ascii estructurado, etc.); o la presentación de los datos en pantalla de múltiples maneras (tabulada, gráfica, etc.) para facilitar la comparación. Si además estos servicios se ofrecen de manera gratuita a través de web, la masiva consulta del sitio está casi asegurada. No obstante, generalmente se opta por el pago de cada uno de los servicios, especialmente cuando se trata de los recursos descritos en la tercera categoría, que no sólo tratan la información sino que ésta es reelaborada por expertos para facilitar la toma de decisiones, por ejemplo, con respecto al riesgo. No obstante, podría pensarse que los productores de la primera y segunda categoría podrían subsistir aplicando técni- cas de benchmarking si alcanzan un número suficiente de visitas, ya que la publicidad especializada insertada en webs gratuitas ha sido hasta ahora una de las principales fuentes de ingresos.

\section{Bibliografía}

Aguado Correa, R.; García Ordaz, M. "Consumo de información en la empresa española: análisis de su procedencia y destino. En: Estudios de economía aplicada: VII Reunión anual de Asepelt-España, 1993, v. 4, pp. 202-211.

Baiget, T. "Uso de información en laboratorios farmacéuticos". En: El profesional de la información, 1999, v. 8, n. 12, pp. 15-21.

http://eprints.rclis.org/archive/00008331/

Baiget, T. Información electrónica. España. 1997-2003. Informe integrado con las opiniones un panel de 29 expertos españoles. MSStudy II, jun. 1999

http://www.asedie.es/msstudy/informe.htm

Baiget, T. "Mercat de la informació electrònica a Catalunya. Comparació amb la resta d'Espanya". En: Item, 1999, n. 25, pp. 6-26

Bonson Ponte, E.; Cortijo Gallego, V.; Escobar Rodríguez, T. "La demanda de información financiera empresarial en internet". En: Partida doble, 2003, n. 144, pp. 40-55.

Código de comercio, de 22 de agosto de 1885 . BOE 24-11-1885.

http://www.igsap.map.es/cia/dispo/25355.htm

Cornella,A. La informació digital per a l'empresa a Catalunya. Barcelona: Marcombo, 1996.

Cornella, A. Información digital para la empresa: una introducción a los servicios de información electrónica. Barcelona: Marcombo, Boixareu, 1996.

Ferrer Sapena, A. "Ecsocial.com. Servicio de información para la economia social". En: Noticias de la economía pública, social y cooperativa, 2005, junio, n. 44, pp. 63-65.

Gabás Trigo, F.; Moneva Abadía, J.; Bellostas Pérez-Grueso, A. J.; Jarne Jarne, J. I. "Análisis de la demanda de información financiera en la coyuntura actual”. En: Revista española de financiación y contabilidad, 1996, v. 26, n. 86, pp. 103-137

García Palomeque, R.; Navarro Méndez, I. "El paper dels documentalistes a l'empresa de serveis: dues experiències". En: Item, 2005, n. 40, pp. 127-142.

Giménez Toledo, E.; Román Román, A. "Productores de información interesantes para las empresas. Resultados de una encuesta sobre consumo de información a empresas de la comunidad de Madrid". En: Revista general de información y documentación, 2003, v. 13, n. 2, pp. 73-92.

Guallar, J.; Cornet Casals, A. "Fuentes de información digitales en los centros de documentación de prensa: las bases de datos comerciales". En: El profesional de la información, 2004, v. 13, n. 2, pp. 107-117. http://eprints.rclis.org/archive/00007858/01/epimar04_guallar-cornet_fuentes 1.pdf

Ley 27/1999, de 16 de julio de cooperativas. BOE 17-11-99.

http://empleo.mtas.es/empleo/economia-soc/NoticiasDoc/Def_noticias.htm

Muñoz Cruz, V. "El papel del gestor de la información en las organizaciones a las puertas del siglo XXI". En: VI Jornadas españolas de documentación ¿los sistemas de información al servicio de la sociedad?

http://fesabid98.florida-uni.es/Comunicaciones/ v_munyoz.htm

Ojala, M. "When business meets science". En: Online, 2005, Nov.-Dec., pp. 46-47.

http://www.onlinemag.net

Ojala, M. "The future of directory information". En: Online, 2005, Sept.-Oct., pp. 38-39.

http://www.onlinemag.net

Ordóñez Vergara, M. J. "El consumo de información en la industria farmacéutica. I. Resultados del análisis de la demanda al Cindoc". En: Revista española de documentación científica, 1999, v. 22, n. 4, pp. 472-487.

Ordóñez Vergara, M. J. "El consumo de información en la industria farmacéutica. II. Resultados de una encuesta". En: Revista española de documentación científica, 2000, v. 23, n. 2, pp. 179-198.

Ordóñez Vergara, M. J. "Información y desarrollo industrial". En: La gestión del conocimiento: retos y soluciones de los profesionales de la información: VII Jornadas españolas de documentación, 2000, pp. 487-498.

Paños Alvarez, A. "Reflexiones sobre el papel de la información como recurso competitivo de la empresa". En: Anales de documentación, 1999, n. 2, pp. 21-38.

Paños Alvarez, A.; Pastor Sánchez, J. A.; Martínez Méndez, F. J. "Análisis y potencialidad de los recursos de información empresarial de la región de Murcia". En: Revista española de documentación científica, 1998, v. 21, n. 4.

http://www.um.es/gtiweb/fjmm/analisis.html

Pérez Álvarez-Ossorio, J. R. "Demanda de información de la industria española". En: Revista española de documentación científica, 1986, v. 9, n. 4, pp. 373-385.

Portela Peña, P. Directorios españoles de información de la economía española. Barcelona: Crítica, 1996.

Portela Peña, P. "La información económica en España”. En: El profesional de la información, 1999, v. 8, n. 12 , pp. 4-14.

Sanz, E.; Rubio, L. "Necesidades de información en las empresas: estudio de un caso". En: Revista española de documentación científica, 1993, v. 16, n. 3, pp. 229-236.

Antonia Ferrer y Fernanda Peset, Departamento de Comunicación Audiovisual, Documentación e Historia del Arte, Universidad Politécnica de Valencia.

anfersa@upv.es

mpesetm@upv.es 